\title{
THE ORTHODONTIC MANAGEMENT OF AN ADULT WITH SICKLE CELL DISEASE
}

\author{
K.G AMOAH ${ }^{1}$, M. NEWMAN-NARTEY ${ }^{1}$ and I. EKEM ${ }^{2}$ \\ ${ }^{1}$ Department of Orthodontics and Paedodontics, University of Ghana Dental School, Accra Ghana, \\ ${ }^{2}$ Department of Haematology Korle-Bu Teaching Hospital, Accra, Ghana
}

DOI: http://dx.doi.org/10.4314/gmj.v49i3.13

Corresponding Author: Dr. Kwabena Gyaami Amoah

Email:gyaami@yahoo.co.uk

Conflict of interest: none declared

\section{SUMMARY}

Sickle cell disease (SCD) is a hereditary blood disorder characterized by abnormally shaped red cells. SCD frequently exhibits multisystemic manifestations including oral and craniofacial disorders. Craniofacial features such as maxillary protrusion and more forward growth of the mandible with significantly retruded maxillary and mandibular incisors are common. When a patient with Sickle Cell Disease (SCD) needs orthodontic treatment, it is important for the practitioner involved to know about the disease and the respective treatment because of the importance of complete blood supply after application of intraoral and extraoral forces. This article describes a sickle cell HbSS patient with orthodontic problems and how she was successfully managed at the University of Ghana Dental School.

Keywords: sickle cell disease, orthodontic treatment, craniofacial features, gnatopathy

\section{INTRODUCTION}

Sickle cell disease (SCD) is the most common serious genetic disorder in sub-Saharan Africa. About 2\% of newborns in Ghana have SCD, and in the general population about $25 \%$ have the trait. ${ }^{1,2}$ The principal genotypes include homozygous sickle cell anaemia, sickle cell haemoglobin $\mathrm{C}$ disease, and sickle cell- $\beta$ thalassaemia. The pathologic effects of sickle cell anemia, demonstrated in mineralized connective and connective tissues in other areas of the body, also occur in oral tissues. ${ }^{3}$

Several oral findings described in the literature include uncommon degree of periodontitis, hypomaturation and hypomineralization in enamel and dentin and bone alterations resulting in maxillary protrusion and formation of thick trabecular pattern. ${ }^{3,4}$ Osteoporosis of the alveolar crest has been identified by radiographic examination. ${ }^{6,7,89}$ Odonkor ${ }^{10}$ has shown that the chang- es seen radiographically involving maxillofacial and dental tissues are similar to those observed in cases of rickets, fluorosis and after thyroidectomy.

Craniofacial features, such as maxillary protrusion and more forward growth of the mandible with significantly retruded maxillary and mandibular incisors referred to in FID Konotey-Ahulu's book (pp178-188) as gnathopathy, have also been documented in black American children with SCD. ${ }^{11,12}$ In a study of 36 Sicilian patients with SCD, Licciaderllo et al., ${ }^{13}$ showed that the clinical craniofacial manifestations were of moderate severity compared to that observed in the black American children.

According to Mourshed and Tuckson ${ }^{14}$ the most frequent oral manifestations of SCA include paleness of the oral mucosa, delays in tooth eruption, atrophy of the tongue papillae, impaired dentine mineralization, mandibular osteomyelitis, and orofacial pain.

Craniofacial alterations in SCD patients occur as the result of hyperplasia and compensatory expansion of the bone marrow, resulting in exaggerated growth/ protrusion of the midface, maxillary expansion, a predominance of vertical growth, mandibular retrusion, a convex profile, and maxillary protrusion. ${ }^{7,11,13,15,16-19}$ Other studies however have shown that the facial features of SCA patients are similar to those characteristics of patients without SCA and that these patients showed no compensatory maxillary expansion. ${ }^{20}$

Literature is scarce on case reports involving sickle cell patients undergoing orthodontic treatment, however two of such cases have been reported by Oluwatosin et $a l^{21}$ and Pithon. ${ }^{22}$ In this report special measures were taken to ensure that the patient did not present in any vaso-occlusive crisis. 
Measures taken included antibiotic cover before any invasive procedure; scheduling of dental appointments for early morning and care taken to avoid any emotional stress and multidisciplinary care including the physician or haematologist of the patient.

\section{CASE REPORT}

A 25-year-old female with SCD presented at the University of Ghana Dental School with the complaint that she did not like the appearance of her teeth, her smile and her profile. She also complained that she could not bring her lips together without difficulty

\section{Extra-oral assessment}

On examination, she had mandibular retrognathia, bimaxillary protusion and difficulty in closing lips because of the protrusive nature of her dentition. She had slightly increased facial proportions with no noticeable asymmetries.

\section{Intra-oral assessment}

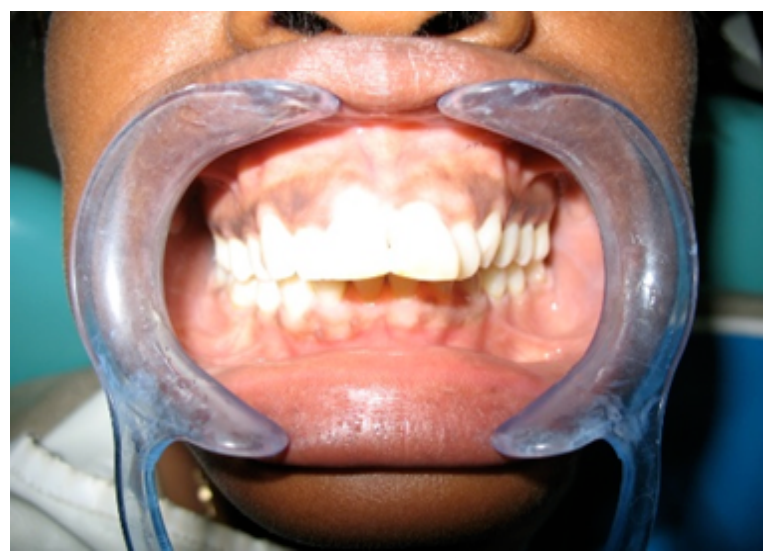

Figure 1 Pre-treatment intraoral photograph

The patient presented with acceptable oral hygiene. Both mandibular and maxillary arches were narrow and V-shaped. She also had a high arched palate with mild crowding in the upper arch. Her two upper central incisors were slightly discoloured at the incisal edges. She presented with a severe overjet (horizontal distance between upper incisors and lower incisors) of $12 \mathrm{~mm}$ (normal overjet being 2-3mm), a deep overbite (vertical overlap of the lower incisors by the upper incisors) and incompetent lips.

Her molar relationship was class I on the right and class II on the left. Her upper and lower incisors were severely proclined. A dental panoramic radiograph revealed the presence of all permanent teeth. A cephalometric radiograph confirmed the increased overjet, bimaxillary proclination and Class II skeletal pattern.

\section{Aims and objectives of treatment}

Due to the established skeletal pattern and very little growth remaining in the patient, the aim was to camouflage the class II skeletal pattern, reduce the overjet and overbite to normal levels and to relieve crowding in upper arch and eliminate the incompetency of the lips

\section{Treatment plan}

The plan was to extract upper first premolar teeth on each side of the maxilla to aid in the reduction of the overjet and mild crowding with the aid of a Nance palatal button followed by upper and lower Roth $0.022 \times 0.028$ pre-adjusted edgewise fixed orthodontic appliance system. Retention after treatment was to be provided using removable Hawley retainers
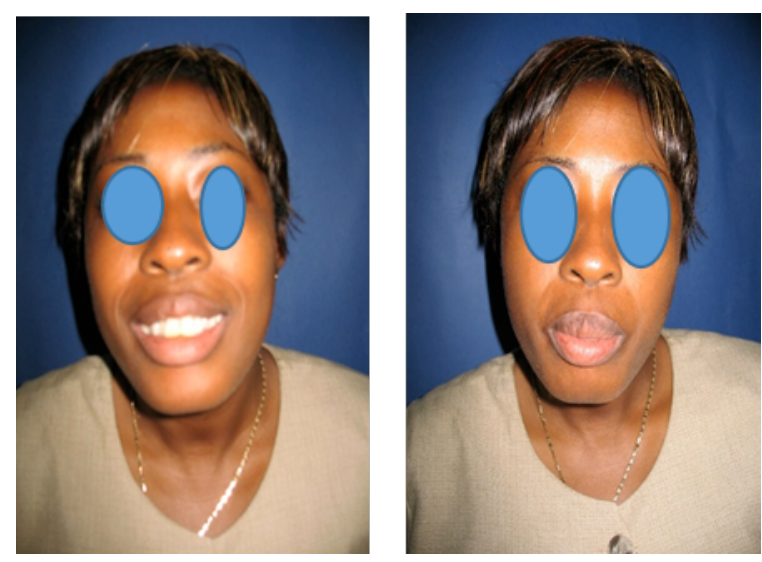

Figure 2(a and b) Pre-treatment extra-oral photographs

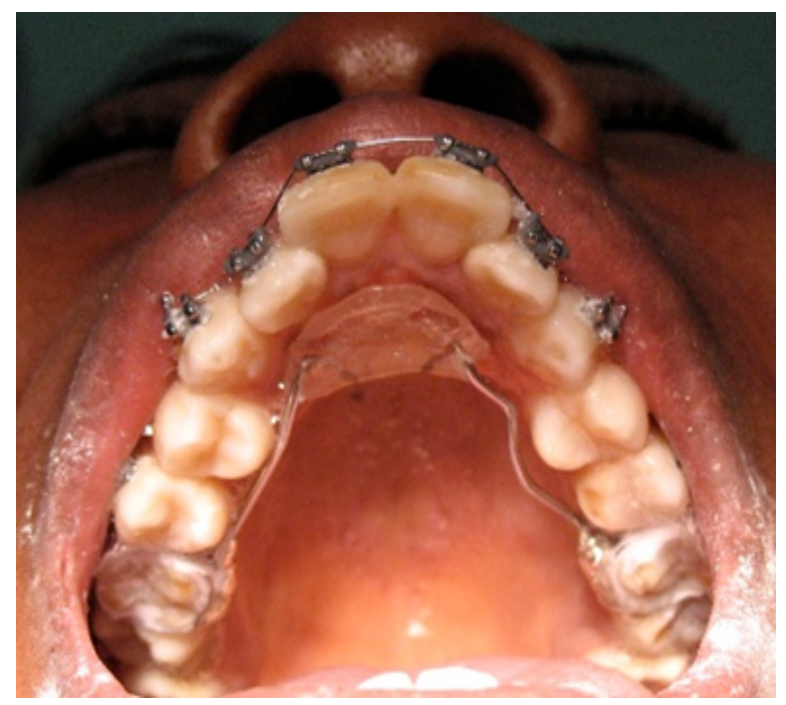

Figure 3 intraoral photograph showing fixed braces with Nance button 


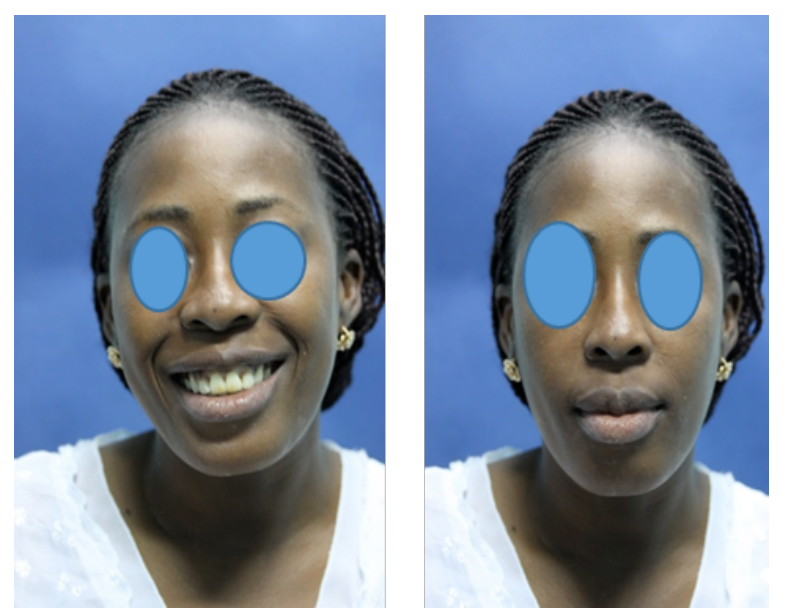

Figure 4 (a and b) Post-treatment extra-oral photographs

\section{Treatment progress}

After explaining the treatment procedure and the signing of a consent form during which the patient agreed to the use of her records for scientific publications, research and teaching, treatment was started. Consenting before treatment is routinely done for every patient attending the clinic and patients are under no compulsion to sign this form

Treatment involved fixed orthodontic braces over a 24 month duration involving the elective extractions of the first premolar teeth on each side of the maxilla under local anaesthesia using $20 \mathrm{mg} / \mathrm{ml}$ lidocaine hydrochloride $1: 80,000$. This was necessary because space was needed to retract the upper anterior teeth to reduce the severe overjet. After extractions were performed the patient was monitored for about two hours to be sure all bleeding had stopped before being discharged.

Due to her medical history, before the extractions were done, a full blood count was undertaken. Adequate antibiotic cover of Amoxycillin 500mg three times daily for one week was also given after the extraction. During orthodontic treatment, emotional stress was avoided and care was taken to have adequate levels of oxygenation, good hydration and ambient temperature. The use of very light orthodontic forces was also used to avoid causing vaso occlusive crisis in the local blood circulation.

Thus the patient was seen monthly and archwire changes were done after every other visit. The use of acetylsalicylic acid as an analgesic was avoided in cases where painful episodes were encountered because this drug changes patient's platelet's adhesion capacity which may cause bleeding during the procedures, in- duces intestinal and gastric ulceration and may cause hepatic lesions in SCD patients

During the treatment, long extensive procedures were avoided and her appointments were scheduled for early morning. The oral hygiene status of the patient was put under strict control by the Dental Hygienists to avoid any episodes of gingivitis during the treatment. There was also close collaboration with the sickle cell clinic which she attended. After the braces were removed she was given Hawley retainers and she went through the retention regime for 1 year successfully.
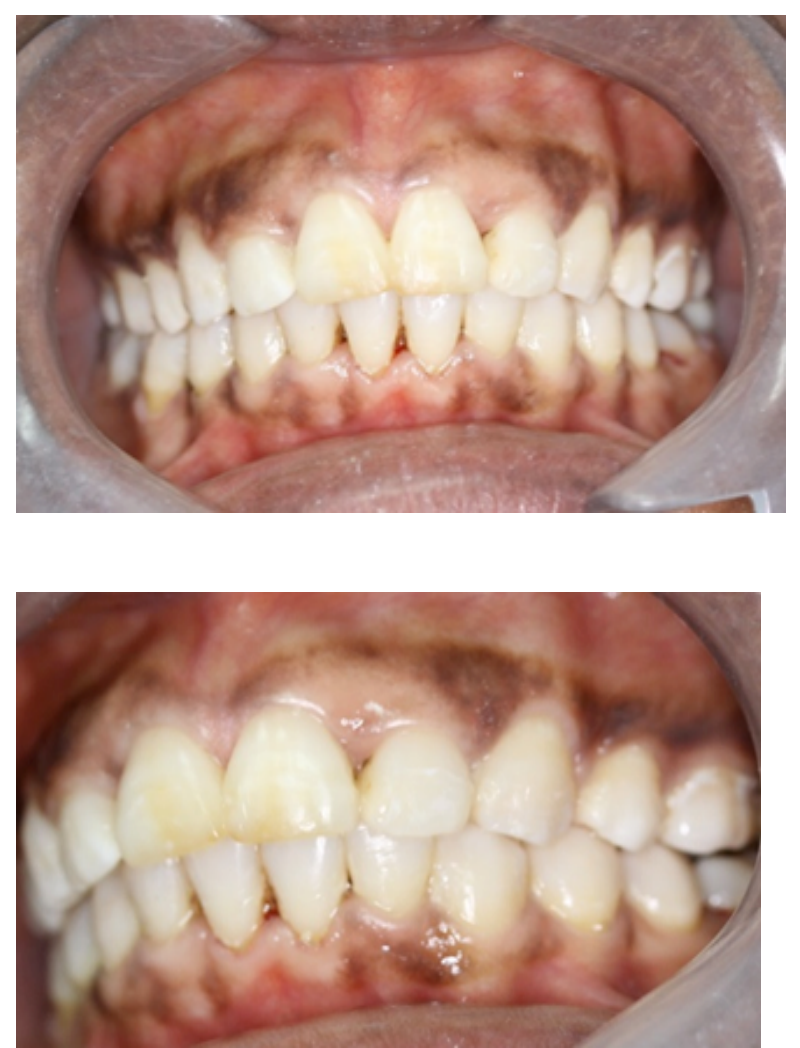

Fig. 5 (a and b) Post-treatment intraoral photographs

\section{DISCUSSION}

Orthodontic treatment of patients diagnosed with SCD presents a challenging situation not only to the Orthodontist, but to the medical team as a whole due to the numerous other complications associated with the disease. There are very few published articles in the orthodontic literature describing the orthodontic treatment of patients with SCD and as such there is no established protocol for the treatment of such patients. Most articles ${ }^{4,21,23,24}$, which describe management of dental patients are not based on any longitudinal or clinical study and majority of them ${ }^{4,23-25}$ state that elective surgeries such as the extraction of asymptomatic teeth for orthodontic treatment are contraindicated. 
This may be due to the fact that oral infections are considered a high risk factor in the precipitation of a sickle cell crisis ${ }^{25}$. In the above named patient however the malocclusion was so severe that the only reasonable option was to extract two upper premolar teeth. This was done after preventive measures like taking a full blood count and notification of the physician of the patient.

Franco et al. ${ }^{26}$ suggested that $2 \mathrm{~g}$ of Amoxycillin should be given $1 \mathrm{hr}$ before any invasive dental procedure in a sickle cell patient, however there is no evidence-based guideline for premedication of patients with sickle cell disease. In this patient $500 \mathrm{mg}$ of amoxycillin three times daily for one week was prescribed after the extractions. It must be noted that the latter regimen is routinely carried out for patients with SCD undergoing orthodontic extractions at the University of Ghana Dental School and so far no complications have been reported. This same prophylactic measure is also used for patients without SCD undergoing orthodontic treatment.

\section{CONCLUSIONS}

In the above patient, all the pretreatment objectives were realized namely reduction in the overjet and overbite to normal values, the relief of the mild crowding, and the camouflage of the class II skeletal pattern. The lip incompetence was also corrected; as such the patient was able to close the lips together without any strain of the perioral muscles.

Our case shows that the quality of life for patients suffering from SCD can be improved for those presenting with craniofacial disorders, when they seek dental treatment. Sickle cell patients with craniofacial manifestations should thus be encouraged to seek oral health and advice at an early stage since most of these severe manifestations are easily managed in growing children.

In the treatment of patients suffering from SCD, special care must be taken to avoid excessive stress and forces. Care should also be taken when extractions are indicated and as much as possible this should be done in a hospital environment. The extraction of teeth and the prescribing of 500mg Amoxycillin three times daily post extraction for one week also proved successful without any adverse effects and this is routinely used for other sickle cell patients undergoing orthodontic treatment

\section{REFERENCES}

1. Ohene-frempong K, Oduro J, Tetteh H, Nkrumah F. Screening newborns for sickle cell disease in Ghana. Pediatrics 2008; 121 (suppl 2): 120-121
2. Konotey-Ahulu FID. The sickle cell disease patient. Tetteh-A'domeno Publishing Company. 1991:pp 178-188

3. Franco BM, Goncalves JCH, dos Santos CRR. Buccal manifestations of sickle cell anemia and their implications in the dentistry services. Arq Odontol 2007; 92-96

4. Alves PV. Alves DK, de Souza MM, Torres SR. orthodontic treatment of patients with sickle cell anemia, Angle orthod 2006; 76: 269-73

5. Kelleher M, Bishop K, Briggs P. oral complications associated with sickle cell anemia: a review and case report. Oral surg oral med oral pathol oral radiol endod 1996; 82:225-8

6. Levine RS, Keen JH. Neonatal enamel hypoplasia in association with symptomatic neonatal hypocalcaemia. Br Dent J. 1974;137:429-433

7. Saint Clair de Velasquez Y, Rivera H. sickle cell anemia oral manifestations in a Venezuelan population. Acta Odontol Latinoam. 1997;10:101-110

8. Olaitan AA, Amuda JT, Adekeye EO. Osteomyelitis of the mandible in sickle cell disease. $\mathrm{Br} J$ oral maxillofacial surg. 1997;35: 190-192

9. Michaelson J, Bhola M. oral lesions of sickle cell anemia: case report and review of literature. $J$ Mich Dent Assoc. 2004;86:32-35

10. Odonkor PO. Metabolic and endocrine basis of growth retardation in sickle cell disease. Bull Eur Physiopathol Respir.1983; 19:357-359

11. Altemus L A, Epps C W 1974 Cephalofacial characteristics of North American individuals with sickle cell disease. Quarterly of the National Dental Association $32: 80-88$

12. Shnorkian H I, Chapman D C, Nazif N M, Zullo T G 1984 Cephalometric study of American black children with sickle-cell disease. ASDC Journal of Dentistry for Children 6:431-433

13. Licciardello V, Bertuna G, Samperi P. Craniofacial morphology in patients with sickle cell disease: a cephalometric analysis. Eur J Orthod. 2007;29: 238-242

14. Mourshed F, Tuckson CR. A study of the radiographic features of the jaws in sickle-cell anaemia. Oral Surg Oral Med Oral Pathol. 1974;37:812819.

15. Brown DL, Sebes JL. Sickle cell gnathopathy: radiologic assessment. Oral Surg Oral Med Oral Pathol. 1986; 61: 653-656

16. Taylor LB, Nowak AJ, Giller RH, Casamassimo PS. Sickle cell anaemia: a review of dental concerns and a retrospective study of dental and bony changes. Spec Care Dentist. 1995;15:38-42.

17. Oredugba FA, Savage KO. Anthropometric finding in Nigerian children with sickle cell disease. Pediatr Dent. 2002;24:321-325. 
18. Faber TD, Yoon DC, White SC. Fourier analysis reveals increased trabecular spacing in sickle cell anaemia. J Dent Res. 2002;81:214-218

19. Onyeaso CO, da Costa OO. Dental aesthetics assessed against orthodontic treatment complexity and need in Nigerian patients with sickle-cell anaemia. Spec Care Dentist. 2009;29:249-253.

20. Maia NG, dos Santos LA, Coletta RD, Mendes PH, Bonan PR, Maia LB, Martelli Junior H. Facial features of patients with sickle cell anemia Angle Orthod. 2011;81:115-120.

21. Oluwatosin SO, Oredugba AF, Edamisan TO. Orthodontic management of traumatic avulsion of permanent incisors in a child with sickle cell anemia: case report. Cases Journal 2009; 2:8123

22. Pithon MM. Orthodontic treatment in a patient with sickle cell anemia. American journal of orthodontics and dentofacial orthopedics 2011;140(5):713-9.
23. Deirdre R. Sams DJBT, DMD, MA Paul A. Amamoo, MD. Managing the dental patient with sickle cell anemia: a review of the literature. Pediatric Dentistry. 1990;12(5):5.

24. Rouse LE, Hays GL. Dental considerations in sickle cell anemia. General dentistry 1979;27(6):18-9

25. Smith HB, McDonald DK, Miller RI. Dental management of patients with sickle cell disorders. The Journal of the American Dental Association. 1987;114(1):85-7.

26. Franco BM, Goncalves JCH, dos Santos CRR. Buccal manifestations of sickle cell anemia and their implications in the dentistry services. Arq Odontol 2007;43:92-6 